\title{
The Effect of Adenotonsillectomy on Growth in Prepubertal Children
}

\author{
Sang Min Hyun, $\mathrm{MD}^{1}$, Do-Youn Kim, $\mathrm{MD}^{2}$, Jong Sook Yi, MD³ , Bong-Jae Lee, MD², Yoo-Sam Chung, MD, PhD² \\ ${ }^{1}$ Shimmian ENT Clinic, Seoul, Korea \\ 2Department of Otolaryngology, Asan Medical Center, University of Ulsan College of Medicine, Seoul, Korea \\ ${ }^{3}$ Department of Otolaryngology, CHA Bundang Medical Center, Seongnam, Korea
}

\begin{abstract}
Background and Objective To document the effect of adenotonsillectomy on prepubertal growth in children according to preoperative growth status and follow up period.

Methods The clinical records of 161 prepubertal children with sleep breathing disorder who underwent adenotonsillectomy between 1998 and 2007 were assessed. The height, weight and body mass index (BMI) was converted to z-score (standard deviation scores) for their ages. Preoperative growth status was divided to three groups (less than 25th percentile, 25-75th percentile, and more than 75th percentile). The changes of weight, height and BMI were evaluated according to follow up periods and preoperative growth status.
\end{abstract}

Results The slopes ( $\Delta z$-score/year) of general parameters (height, weight, BMI) were not significant statistically. For height-for-age, < 25th percentile group had significant increase of $z$-score by 0.155 per year $(p=0.009)$, but the other groups did not. For weight-for-age, z-score of $25-75$ th percentile group was increased by 0.119 per year $(\mathrm{p}=0.010)$ and $\mathrm{z}$-score of $>75$ th percentile group was decreased significantly by 0.096 per year $(\mathrm{p}=0.039)$. But for BMI-for age, the slopes of all groups were not significant statistically.

Conclusions Adenotonsillectomy could make constant increase of height during prepubertal period for $<25$ th percentile children. Also adenotonsillectomy make constant increase of weight for 25-75th percentile children, and make decrease of weight for $>75$ th percentile children during prepubertal period. Adenotonsillectomy might have different effects on growth indices of children with sleep disordered breathing according to initial growth status.

Sleep Med Res 2016;7(1):21-25

Key Words Adenotonsillectomy, Growth, Children.

Received: June 8, 2016

Revised: June 17, 2016

Accepted: June 20, 2016

\section{Correspondence}

Yoo-Sam Chung, MD, PhD

Department of Otolaryngology,

Asan Medical Center,

University of Ulsan College of Medicine,

88 Olympic-ro 43-gil,

Songpa-gu, Seoul 05505, Korea

Tel $+82-2-3010-3710$

Fax +82-2-489-2773

E-mail entysc@gmail.com

\section{INTRODUCTION}

Adenotonsillar hypertrophy (ATH) is the most common cause of obstructive sleep apnea syndrome in children, ${ }^{1}$ and the prevalence of obstructive sleep apnea syndrome (OSAS) were at least $1-3 \%$ in children. ${ }^{2}$ Sleep disordered breathing (SDB) is often associated with loud snoring, daytime sleepiness, and daytime mouth breathing. Complications of SDB may include failure to thrive, nocturnal enuresis, sweating during sleep, reduced neurocognition, behavioral problem, and school performances..$^{3-5}$ Several possible mechanisms for failure to thrive have been assessed.

Interruption of the insulin-like growth factor-I axis secondary to abnormal nocturnal growth hormone secretion, ${ }^{6}$ low caloric intake caused by poor appetite and dysphagia, ${ }^{7}$ recurrent tonsillitis, ${ }^{8}$ and high energy expenditure as a consequence of increased work of breathing during sleep ${ }^{9}$ had been proposed as causes. Also many studies had suggested and proved that growth failures were improved after adenotonsillectomy in children with ATH. ${ }^{10-12}$

On the other hand, obesity could be one of the risk factor for SDB in children. ${ }^{13}$ There were few studies about the effect of adenotonsillectomy in obesity children, instead it was reported that children who undergo adenotonsillectomy could be at risk to develop overweight in the years after surgery. ${ }^{14}$ The effect of SDB and adenotonsillectomy on children might be different according to the growth status, but little is known in this aspect. 
Linear growth within the first 2 year of life generally decelerates but then remains relatively constant throughout childhood until the onset of the pubertal growth spurt. ${ }^{15}$ Shifts in growth rates were least common for children 24 to 60 months of age. ${ }^{16}$ During this period, we could analyze concretely the effect of adenotonsillectomy on children growth according to follow up period. The aim of this study is to document the effect of adenotonsillectomy on prepubertal growth in children according to preoperative growth status and follow up period.

\section{METHODS}

\section{Study Design and Patients}

This study was approved by the Institutional Review Board of the Asan Medical Center in Seoul, South Korea. The study involved 2252 prepubertal children with more than 36 months of age who underwent adenotonsillectomy for treatment of SDB between January 1998 and December 2007. Data were extracted only from measurements made during routine visits not from those made because of illness or hospitalization after adenotonsillectomy. Data were included only the children who are measured both weight and height in the outpatient clinic. Children with visits made until prepubertal periods $(3 \leq$ male $<10$, $3 \leq$ female $<9$ ) were included in study. We excluded children with serious congenital anomalies, metabolic disease, syndrome with growth retardation, and precocious puberty. We also excluded children who had first visit within 6 months after adenotonsillectomy, because it might be too short period to change the growth status. Therefore, our final analyses included 161 children with 422 height and weight measurements. We diagnosed SDB by clinical symptoms and physical exam. Children were asked to quantify their subjective symptoms, including snoring, sleep disturbance, effort breathing and apnea preoperatively. To objectively evaluate the SDB, physical exam of measuring tonsil size was performed.

\section{Methods}

We used the 2007 Korean National Growth Charts ${ }^{17}$ to assign height-for-age, weight-for-age, and body mass index (BMI)for-age percentiles for each child's measurements, and to convert the height, weight, and BMI to z-score (standard deviation scores) for their ages. Korean National Growth Charts were obtained from children in 1998 and 2005. Modified LMS method ${ }^{18}$ was used to fit smooth centile curves to the growth charts. Height, weight, BMI percentiles were obtained for boys and girls separately using the modified LMS method ${ }^{18}$ in Korean National Growth Charts, ${ }^{17}$ and we found out $\mathrm{z}$-score from L (Box-Cox Poser), M (median), S (coefficient of variation) value which was defined according to the gender, and ages in Korean National Growth Charts.

$\mathrm{Z}=\left\{\left[(\mathrm{X} / \mathrm{M})^{\mathrm{L}}\right]-1\right\} / \mathrm{LS}$ (Z: z-score, $\mathrm{X}$ : given measurement)

We also divided children to 3 groups, respectively $(<25$ th percentile, $25-75$ th percentile, $>75$ th percentile) according to preoperative height, weight, and BMI. We analyzed the changes of $\mathrm{z}$-score ( $\Delta \mathrm{z}$-score) for height, weight, and BMI according to postoperative period and compared $\Delta z$-score between 3 groups.

$\Delta \mathrm{z}$-score $=$ (z-score of routine visit after adenotonsillectomy)

- (z-score before adenotonsillectomy)

\section{Statistical Analysis}

We calculated the slopes ( $\Delta \mathrm{z}$-score/year) of general parameters (height, weight, BMI) and difference of the slopes between groups by linear mixed model. Statistical analyses were performed using SAS (version 9.1.3, SAS Institute, Inc., Cary, NC, USA), and $\mathrm{p}<0.05$ was considered to indicate a significant difference.

\section{RESULTS}

The study involved 161 children (117 males and 44 females) who underwent adenotonsillectomy for SDB. The mean age of the 161 children at adenotonsillectomy was $5.20 \pm 0.42$ years (range, 3-9 years). The mean number of hospital visits after adenotonsillectomy were 1.62 that 97 children (60.25\%) had 1 visit, 31 children (19.25\%) had 2 visits, 30 children (18.63\%) had 3 visits, and 3 children (1.86\%) had 4 visits. The mean period between measurement and adenotonsillectomy was 29.4 months ranged 6 months to 73 months. Table 1 shows the distribution of preoperative age-for-height, age-for-weight and agefor-BMI.

The slopes ( $\Delta \mathrm{z}$-score/year) of height for total children were $0.036 /$ year, and were not significant statistically $(\mathrm{p}=0.224)$. But $<25$ th percentile group of height had significant increase of $\mathrm{z}$ score by 0.155 per year $(p=0.009) .25-75$ th group of height had increase of $z$-score by 0.061 per year $(p=0.181)$, and $>75$ th group of height had decrease of $\mathrm{z}$-score by 0.088 per year $(\mathrm{p}=0.084)$,

Table 1. Distribution of preoperative age-for-height, age-for-weight, and age-for-BMI

\begin{tabular}{lccc}
\hline & $<25$ th percentile & 25-75th percentile & $>75$ th percentile \\
\hline Height & $42(26 \%)$ & $61(38 \%)$ & $58(36 \%)$ \\
Weight & $35(22 \%)$ & $70(43 \%)$ & $56(35 \%)$ \\
BMI & $38(24 \%)$ & $69(43 \%)$ & $54(33 \%)$ \\
\hline
\end{tabular}

BMI: body mass index 
but both of two groups were not significant statistically. And the difference between three groups of height had statistical significance $(\mathrm{p}=0.0062)$ (Fig. 1 , Table 2$)$.

The slopes of weight for total children were 0.034 /year, and were not significant statistically ( $\mathrm{p}=0.242$ ), and $<25$ th percentile group of weight had increase of $\mathrm{z}$-score by 0.095 per year, but did not have statistical significance $(\mathrm{p}=0.132)$. 25-75th percentile group of weight had significant increase of $\mathrm{z}$-score by 0.119 per year $(p=0.010)$, and $>75$ th percentile group of weight had significant decrease of $\mathrm{z}$-score by 0.096 by per year $(\mathrm{p}=$

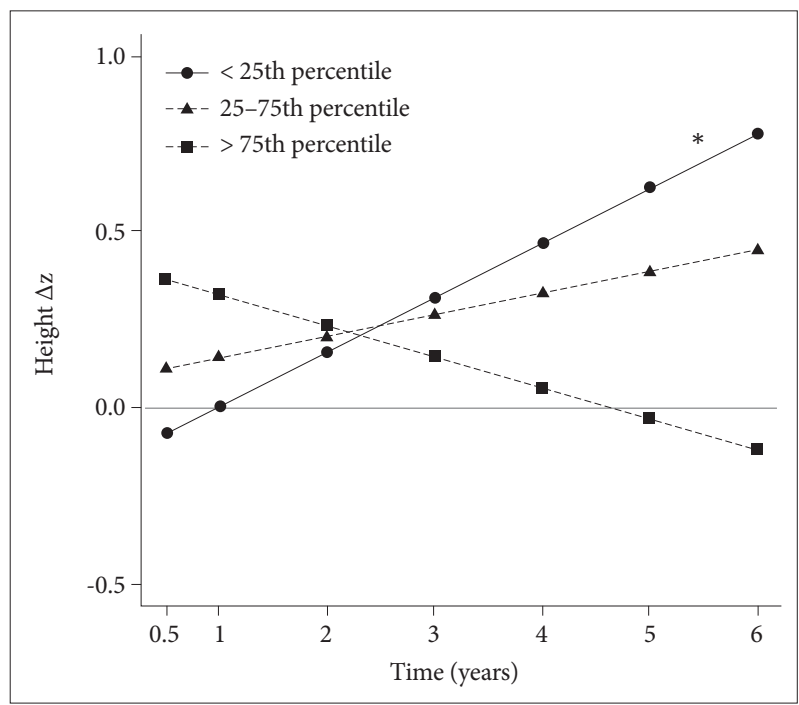

Fig. 1. Change of $\Delta z$-scores for each group (height) after adenotonsillectomy. $<25$ th percentile group had constant increase of zscore and the slopes ( $z$-score/year) were $0.155 /$ year $\left({ }^{*} p=0.009\right)$ and the growth was statistically significant.
$0.039)$. The slopes between three groups were differed statistically ( $\mathrm{p}=0.0025)$ (Fig. 2, Table 2). The slopes of BMI for total children were $0.009 /$ year, and were not significant statistically $(\mathrm{p}=$ 0.822 ), and the slopes for each groups were $0.059 /$ year for < 25th percentile group, 0.013/year for 25-75th percentile group, and $-0.041 /$ year for $>75$ th percentile group, respectively. The slopes for all three groups were not significant statistically, and the difference between three groups of BMI did not have statistical significance $(\mathrm{p}=0.589)$ (Table 2).

\section{DISCUSSION}

Among children presenting for ATH or having sleep symptoms assessed, growth failure was at least twice the expected rate, ${ }^{19}$ and adenotonsillectomy had a valuable beneficial effect on children with OSAS. ${ }^{20}$ Several studies had suggested and proved that adenotonsillectomy might increase weight, height, and BMI for child growth. ${ }^{11,21}$ Increase in weight and insulinlike growth factor type 1 levels followed by the increase in height leads to an acceleration in growth rate after adenotonsillectomy. These results have led to the conclusion that either the levels or effect of growth hormone increase following adenotonsillectomy. ${ }^{11,12,21}$ Obstructive sleep apnea (OSA) can also induce obesity. Leptin is a hormone from adipocyte and decrease appetite. ${ }^{22}$ Ghrelin increase appetite and secreted from gut. ${ }^{23}$ The sleep disturbance from OSA may develop leptin resistance and enhance ghrelin secretion, both of which can increase probability of obesity. ${ }^{24,25}$ For the overweight children, adenotonsillectomy may be beneficial to control their weight by

Table 2. Analysis of age-for-height, age-for-weight, and age-for-BMI

\begin{tabular}{|c|c|c|c|}
\hline & Slope* & $\mathrm{p}^{- \text {value }^{\dagger}}$ & p-value ${ }^{\ddagger}$ \\
\hline \multicolumn{4}{|l|}{ Height } \\
\hline Total & 0.036 & 0.224 & \\
\hline$<25$ th percentile & 0.155 & $0.009^{\S}$ & \\
\hline $25-75$ th percentile & 0.061 & 0.181 & $0.0065^{\S}$ \\
\hline$>75$ th percentile & -0.088 & 0.084 & \\
\hline \multicolumn{4}{|l|}{ Weight } \\
\hline Total & 0.034 & 0.242 & \\
\hline$<25$ th percentile & 0.095 & 0.132 & \\
\hline $25-75$ th percentile & 0.119 & $0.010^{\S}$ & $0.0025^{\S}$ \\
\hline$>75$ th percentile & -0.096 & $0.039^{\S}$ & \\
\hline \multicolumn{4}{|l|}{ BMI } \\
\hline Total & 0.009 & 0.822 & \\
\hline$<25$ th percentile & 0.059 & 0.435 & \\
\hline $25-75$ th percentile & 0.013 & 0.829 & 0.5885 \\
\hline$>75$ th percentile & -0.041 & 0.514 & \\
\hline
\end{tabular}

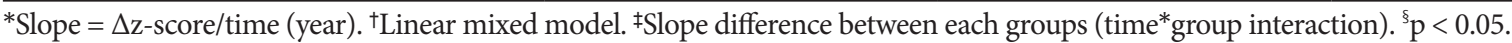
BMI: body mass index. 


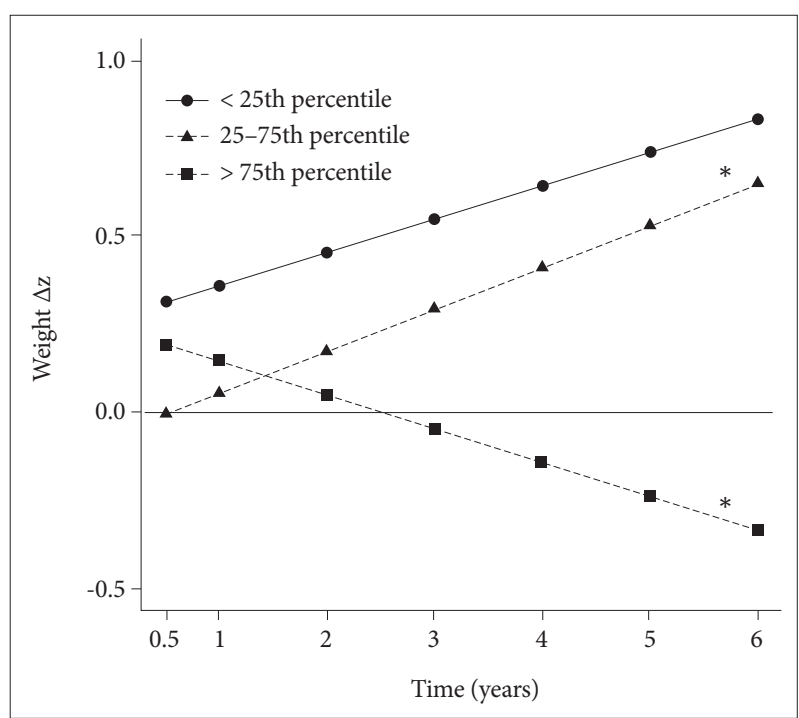

Fig. 2. Change of $\Delta z$-scores for each group (weight) after adenotonsillectomy. 25-75th percentile group had constant increase of $z$-score and the slopes (z-score/year) were $0.119 /$ year $\left({ }^{*} p=\right.$ $0.010)$. $>75$ th percentile group had constant decrease of $z$-score and the slopes (z-score/year) were -0.096/year $(p=0.039)$.

treating OSA. But there were little studies about the effects of adenotonsillectomy considering the time effect and preoperative growth status. We evaluated the effect of adenotonsillectomy in children growth with SDB according to initial growth status and times after surgery. To exclude effects of puberty, we confined the age of surgery and hospital visit from 3 to 10 years for male, and 9 years for female considering that changes of growth rate and percentile were uncommon from 24 months until puberty. ${ }^{15,16}$ And because the 2007 Korean National Growth Charts data were collected from a sample in the 1998 and 2005, the growth patterns of those children might reflect the growth status of this study and the current growth status of children.

We could not find the constant pattern of changes for total children's height, weight, and BMI. But when we divided the children to three groups according to preoperative growth status, $<25$ percentile group of height had constant increase of $\mathrm{z}$ score by 0.155 per year $(\mathrm{p}=0.009) .<25$ percentile group of weight also had constant increase of $\mathrm{z}$-score per 0.095 per year, but there were not statistical significance $(p=0.114)$. Because $<25$ percentile group of weight had smaller sample size $(\mathrm{n}=$ 35) comparing with other groups, it could not make meaningful statistical value. But 25-75th percentile group of weight had constant increase of $\mathrm{z}$-score by 0.119 per year $(\mathrm{p}=0.010)$, $>75$ th percentile group of weight had constant decrease of $\mathrm{z}$-score by 0.096 per year $(\mathrm{p}=0.039)$. Adenotonsillectomy might increase the height of small children $(<25$ th percentile), and change weight to normal range for all children.

We diagnosed SDB by clinical symptoms and physical exam without polysomnography (PSG). PSG has been considered the "gold standard" diagnostic tool to determine which children with symptoms of upper airway obstruction, yet children's symptoms of OSAS improved after adenotonsillectomy regardless of whether apnea is documented by PSG. ${ }^{26,27}$

And one study reported that children with a positive clinical assessment of OSAS but negative PSG have significant improvement after adenotonsillectomy as compared with observation alone. ${ }^{28}$ So we diagnosed SDB children with clinical symptoms, physical exam, and cephalometry.

Present study has the potential limitations commonly found in routine clinical studies. First, because our study was retrospective design, and the techniques of measurement were not tightly controlled, the quality of the anthropometric measurements cannot be assured although the data came from single clinic. Second, because we only include few data (161 children) from initial data (2252 children), we could not assure whether those children could stand for all children who underwent adenotonsillectomy, and we divided children to only three groups according to preoperative growth status cause of small sample size. There might be possibility of difference of growth rate by gender. We used $\mathrm{z}$-score by dividing gender to overcome this problem. Third, there might be a potential selection bias, because some children contributed only 1 follow up measurement, whereas others had more than 1 such measurement in our analysis and follow up periods were not regular. However, all children's measurements were made during routine and not during visits made because of illness or during hospitalizations. Forth, the present study was not randomized controlled trials of surgery vs. no surgery (e.g., "watchful waiting") for children who were suffering from SDB. To make control group for randomized controlled trials, there might be ethical limitation to recommend only watchful waiting for children who were suffering from growth failure and SDB. But instead of making control group, we used 2007 Korean National Growth Charts to analyze the change of the height, weight, BMI percentiles in general population. Fifth, because we diagnosed the SDB by only clinical findings instead of PSG, there could be selection bias. Finally, because the concurrence among different criteria for failure to thrive is low and no single measurement on its own is adequate to identify nutritional growth delay in general population, ${ }^{29}$ we could not analyze the effect on adenotonsillectomy of children with failure to thrive.

But our study could have clinical values that we analyzed the effects of adenotonsillectomy on child growth according to preoperative growth status, and consecutive changes of growth status after surgery.

Adenotonsillectomy might have different effect on growth of children with SDB according to initial growth status. Adenotonsillectomy could make constant increase of height during prepubertal period for $<25$ th percentile children while other groups couldn't. Also adenotonsillectomy might make children's weight with SDB to normal range by making constant increase of weight for 25-75th percentile children, and make decrease of weight for $>75$ th percentile children during prepuber- 
tal period. Primary care providers and specialists should include sleep breathing disorder secondary to ATH in their differential diagnosis of growth failure in general, or short stature in particular.

\section{Conflicts of Interest}

The authors have no financial conflicts of interest.

\section{REFERENCES}

1. Greenfeld M, Tauman R, DeRowe A, Sivan Y. Obstructive sleep apnea syndrome due to adenotonsillar hypertrophy in infants. Int J Pediatr Otorhinolaryngol 2003;67:1055-60.

2. Gislason T, Benediktsdóttir B. Snoring, apneic episodes, and nocturnal hypoxemia among children 6 months to 6 years old. An epidemiologic study of lower limit of prevalence. Chest 1995;107:963-6.

3. Ahlqvist-Rastad J, Hultcrantz E, Melander H, Svanholm H. Body growth in relation to tonsillar enlargement and tonsillectomy. Int J Pediatr Otorhinolaryngol 1992;24:55-61.

4. Gozal D. Sleep-disordered breathing and school performance in children. Pediatrics 1998;102(3 Pt 1):616-20.

5. Kennedy JD, Blunden S, Hirte C, Parsons DW, Martin AJ, Crowe E, et al. Reduced neurocognition in children who snore. Pediatr Pulmonol 2004;37:330-7.

6. Bar A, Tarasiuk A, Segev Y, Phillip M, Tal A. The effect of adenotonsillectomy on serum insulin-like growth factor-I and growth in children with obstructive sleep apnea syndrome. J Pediatr 1999;135:76-80.

7. Williams EF 3rd, Woo P, Miller R, Kellman RM. The effects of adenotonsillectomy on growth in young children. Otolaryngol Head Neck Surg 1991;104:509-16.

8. Aydogan M, Toprak D, Hatun S, Yüksel A, Gokalp AS. The effect of recurrent tonsillitis and adenotonsillectomy on growth in childhood. Int J Pediatr Otorhinolaryngol 2007;71:1737-42.

9. Marcus CL, Carroll JL, Koerner CB, Hamer A, Lutz J, Loughlin GM. Determinants of growth in children with the obstructive sleep apnea syndrome. J Pediatr 1994;125:556-62.

10. Selimoğlu E, Selimoğlu MA, Orbak Z. Does adenotonsillectomy improve growth in children with obstructive adenotonsillar hypertrophy? J Int Med Res 2003;31:84-7.

11. Ersoy B, Yücetürk AV, Taneli F, Urk V, Uyanik BS. Changes in growth pattern, body composition and biochemical markers of growth after adenotonsillectomy in prepubertal children. Int J Pediatr Otorhinolaryngol 2005;69:1175-81.

12. Bonuck KA, Freeman K, Henderson J. Growth and growth biomarker changes after adenotonsillectomy: systematic review and meta-analysis. Arch Dis Child 2009;94:83-91.

13. Redline S, Tishler PV, Schluchter M, Aylor J, Clark K, Graham G. Risk factors for sleep-disordered breathing in children. Associations with obesity, race, and respiratory problems. Am J Respir Crit Care Med 1999;159(5 Pt 1):1527-32.

14. Wijga AH, Scholtens S, Wieringa MH, Kerkhof M, Gerritsen J, Brunekreef
B, et al. Adenotonsillectomy and the development of overweight. Pediatrics 2009;123:1095-101.

15. Rogol AD, Clark PA, Roemmich JN. Growth and pubertal development in children and adolescents: effects of diet and physical activity. Am J Clin Nutr 2000;72(2 Suppl):521S-8S.

16. Mei Z, Grummer-Strawn LM, Thompson D, Dietz WH. Shifts in percentiles of growth during early childhood: analysis of longitudinal data from the California Child Health and Development Study. Pediatrics 2004;113:e617-27.

17. Korea Centers for Disease Control and Prevention, The Korean Pediatric Society, The Committee for Korean Children and Adolescents Growth Standard. 2007 Korean Children and Adolescents Growth Standard (commentary for the development of 2007 growth chart). Seoul: Division of Chronic Disease Surveillance in Korea Centers for Disease Control and Prevention 2007.

18. Ledford AW, Cole TJ. Mathematical models of growth in stature throughout childhood. Ann Hum Biol 1998;25:101-15.

19. Bonuck K, Parikh S, Bassila M. Growth failure and sleep disordered breathing: a review of the literature. Int J Pediatr Otorhinolaryngol 2006;70:769-78.

20. Leiberman A, Stiller-Timor L, Tarasiuk A, Tal A. The effect of adenotonsillectomy on children suffering from obstructive sleep apnea syndrome (OSAS): the Negev perspective. Int J Pediatr Otorhinolaryngol 2006;70:1675-82.

21. Vontetsianos HS, Davris SE, Christopoulos GD, Dacou-Voutetakis C. Improved somatic growth following adenoidectomy and tonsillectomy in young children. Possible pathogenetic mechanisms. Hormones (Athens) 2005;4:49-54

22. Mantzoros CS, Magkos F, Brinkoetter M, Sienkiewicz E, Dardeno TA, Kim SY, et al. Leptin in human physiology and pathophysiology. Am J Physiol Endocrinol Metab 2011;301:E567-84.

23. Overduin J, Figlewicz DP, Bennett-Jay J, Kittleson S, Cummings DE. Ghrelin increases the motivation to eat, but does not alter food palatability. Am J Physiol Regul Integr Comp Physiol 2012;303:R259-69.

24. Tauman R, Serpero LD, Capdevila OS, O’Brien LM, Goldbart AD, Kheirandish-Gozal L, et al. Adipokines in children with sleep disordered breathing. Sleep 2007;30:443-9.

25. Spruyt K, Sans Capdevila O, Serpero LD, Kheirandish-Gozal L, Gozal D. Dietary and physical activity patterns in children with obstructive sleep apnea. J Pediatr 2010;156:724-30, 730.e1-3.

26. Frank Y, Kravath RE, Pollak CP, Weitzman ED. Obstructive sleep apnea and its therapy: clinical and polysomnographic manifestations. Pediatrics 1983;71:737-42.

27. Suen JS, Arnold JE, Brooks LJ. Adenotonsillectomy for treatment of obstructive sleep apnea in children. Arch Otolaryngol Head Neck Surg 1995;121:525-30.

28. Goldstein NA, Pugazhendhi V, Rao SM, Weedon J, Campbell TF, Goldman AC, et al. Clinical assessment of pediatric obstructive sleep apnea. Pediatrics 2004;114:33-43.

29. Olsen EM, Petersen J, Skovgaard AM, Weile B, Jørgensen T, Wright $\mathrm{CM}$. Failure to thrive: the prevalence and concurrence of anthropometric criteria in a general infant population. Arch Dis Child 2007;92:109-14. 